\title{
DOSES DE BORO E CRESCIMENTO RADICULAR E DA PARTE AÉREA DE CULTIVARES DE ARROZ DE TERRAS ALTAS ${ }^{(1)}$
}

\author{
Juliano Corulli Corrêa ${ }^{(2)}$, André de Moraes Costa ${ }^{(2)}$, Carlos Alexandre \\ Costa Crusciol $^{(3)} \&$ Munir Mauad $^{(2)}$
}

\begin{abstract}
RESUMO
O crescimento radicular é favorecido em condições adequadas de disponibilidade de boro no solo e, por isto, a aplicação da dose correta desse micronutriente é de grande importância, para que não ocorra prejuízo no desenvolvimento e na produtividade da cultura de arroz de terras altas, de acordo com a variedade e tipo de solo. $O$ presente trabalho teve como objetivo avaliar a influência das doses de boro no crescimento radicular e da parte aérea, em três cultivares de arroz de terras altas. $O$ experimento foi realizado em casa de vegetação, em vaso com capacidade de $10 \mathrm{~L}$, que continha $8 \mathrm{dm}^{3}$ de solo Latossolo Vermelho distrófico, sendo o delineamento experimental inteiramente casualizado, em esquema fatorial $3 \times 3$, com quatro repetições. Os tratamentos consistiram de três cultivares (Caiapó, Primavera e Maravilha) e três doses de boro $(0,3$ e $6 \mathrm{mg} \mathrm{dm}^{-3}$ ), usando, como fonte, o bórax. A dose de $6 \mathrm{mg} \mathrm{dm}^{-3}$ foi prejudicial tanto à produção de matéria seca da parte aérea como de raiz para o arroz de terras altas. Além de apresentar maior capacidade de absorção de boro, o cultivar Maravilha apresentou-se mais tolerante à elevação da disponibilidade de $B$ no solo, não ocorrendo alterações de comprimento, diâmetro e superfície radicular.
\end{abstract}

Termos de indexação: Oryza sativa, absorção, raiz.

\footnotetext{
(1) Recebido para publicação em maio de 2004 e aprovado em novembro de 2006.

(2) Pós-Graduando em Agricultura, Faculdade de Ciências Agronômicas - UNESP/FCA. Caixa Postal 237, CEP 18603-970 Botucatu (SP). E-mails: correajc@superig.com.br; munirmauad@hotmail.com

(3) Professor do Departamento e Produção Vegetal/Área Agricultura, UNESP/FCA. E-mail: crusciol@fca.unesp.br
} 


\title{
SUMMARY: INFLUENCE OF BORON ADDITION ON GROWTH OF ROOTS AND SHOOT OF UPLAND RICE CROPS
}

\begin{abstract}
Appropriate boron (B) availability in soils favors root growth, and a sufficient supply of this micronutrient is very important for adequate rice development and yield in upland fields, depending on the cultivars and soil type. This study aimed at evaluating the influence of $B$ addition on growth of roots and shoot of three upland rice cultivars. The experiment was carried out in a greenhouse, in $10 \mathrm{~L}$ pots containing $8 \mathrm{~kg}$ of an Hapludox; the experiment was in a completely random $3 \times 3$ factorial design, with four replications. The treatments consisted of three rice cultivars (Caiapó, Primavera, and Maravilha) and three $B$ rates ( 0 , 3 and $6 \mathrm{mg} \mathrm{dm}^{-3}$ ), as borax. The $B$ rate of $6 \mathrm{mg} \mathrm{dm}^{-3}$ boron was deleterious to dry matter yield of both roots and shoot in upland rice. Besides the greater absorption capacity, cultivar Maravilha was more tolerant to high $B$ doses in the soil, thus root length, diameter and surface were not negatively affected.
\end{abstract}

Index terms: Oryza sativa, absorption, root.

\section{INTRODUÇÃO}

No Brasil, o cultivo do arroz de terras altas concentra-se na região do cerrado. O cultivo desse cereal na região centro-oeste tem como um dos objetivos a abertura de novas áreas agrícolas, em virtude da tolerância dessa cultura a solos com baixos teores de nutrientes (Crusciol et al., 1999), dentre eles o boro (Fageria, 2000). As pesquisas referentes ao manejo da fertilidade do solo para cultura de arroz nesse ecossistema restringem-se à calagem e adubação com macronutrientes, sendo escassas as informações sobre fertilização com micronutrientes à cultura, principalmente o boro.

$\mathrm{O}$ boro é exigido em pequenas quantidades pela cultura do arroz, sendo a decisão para aplicar doses adequadas de boro no solo vital para aumentar a produtividade do arroz (Fageria, 1998), exigindo-se cautela por ser o intervalo de deficiência e toxidez bastante estreito (Scivittaro \& Machado, 2004) uma vez que a toxidez pode ser constatada com baixos níveis no solo (Fageria, 1999).

Os resultados dos trabalhos com boro na cultura do arroz têm demonstrado redução no desenvolvimento vegetal e decréscimo no rendimento de grãos (Lopes et al., 1985), em razão do efeito negativo do excesso de boro no solo em determinadas circunstâncias (Obata, 1995). Fageria et al. (2003) observaram que teores acima de $3,0 \mathrm{mg} \mathrm{kg}^{-1}$ de $\mathrm{B}$ no solo tornam-se tóxicos à cultura. Para obter boa produtividade, adota-se valor de teor foliar próximo de $20 \mathrm{mg} \mathrm{kg}^{-1}$; no entanto, este valor é especifico a cada variedade (Malavolta \& Fornasieri Filho, 1983).

O crescimento radicular da planta é influenciado pelos teores de boro no solo (Barber, 1995). Esse elemento é um ativador de enzimas que atuam em diversos processos metabólicos, tais como transporte de carboidratos, metabolismo das auxinas e formação de raízes por meio da divisão, alongamento e junção da parede celular e atividade das membranas celulares (Marschner, 1995; Lund et al., 1996; Ono \& Rodrigues, 1996). Dentre suas funções, vale destacar a participação no alongamento celular, por fazer parte dos polissacarídeos da parede celular, sendo sua desordem nutricional prejudicial ao crescimento radicular (Obata, 1995).

É de fundamental importância o conhecimento de como o cultivar comporta-se na absorção dos nutrientes no campo, em especial o boro, pois existem diferenças interespecíficas para o arroz. Os mecanismos de resposta da cultura de arroz ao boro dependem do genótipo, das diferentes classes de respostas à adubação (Yu et al., 1998), pela capacidade genética diferente, mecanismos ativos e passivos de absorção para o elemento (Dordas \& Brown, 2001), e pela habilidade de mobilizar o complexo B-açúcar-álcool através do floema (Bellaloui et al., 2003), processos que levam os cultivares a uma maior adaptação ao meio.

O objetivo do trabalho foi avaliar a influência das doses de boro no crescimento radicular e da parte aérea, em três cultivares de arroz de terras altas.

\section{MATERIAL E MÉTODOS}

O experimento foi realizado em casa de vegetação, no Departamento de Produção Vegetal da Faculdade de Ciências Agronômicas - UNESP, Campus de Botucatu, São Paulo, no período de março a julho de 2002. O solo utilizado foi proveniente da camada arável, até $20 \mathrm{~cm}$ de profundidade, de um Latossolo Vermelho distrófico com as seguintes características granulométricas, seguindo método descrito por Kiehl (1979) e químicas de acordo com Raij et al. (2001): $800 \mathrm{~g} \mathrm{~kg}^{-1}$ de areia, $200 \mathrm{~g} \mathrm{~kg}^{-1}$ de argila, $\mathrm{B}=$ 
$0,06 \mathrm{mg} \mathrm{dm}^{-3}, \mathrm{pH} \mathrm{CaCl} \mathrm{CH}_{2}=4,1 ; \mathrm{MO}=13 \mathrm{~g} \mathrm{dm}^{-3} ; \mathrm{P}-$ resina $=5 \mathrm{mg} \mathrm{dm}{ }^{-3} ; \mathrm{K}^{+}=0,2 \mathrm{mmol}_{\mathrm{c}} \mathrm{dm}^{-3} ; \mathrm{Ca}^{2+}=$ $5 \mathrm{mmol}_{\mathrm{c}} \mathrm{dm}^{-3} ; \mathrm{Mg}^{2+}=3 \mathrm{mmol}_{\mathrm{c}} \mathrm{dm}^{-3} ; \mathrm{H}+\mathrm{Al}=$ $21 \mathrm{mmol}_{\mathrm{c}} \mathrm{dm}^{-3} ; \mathrm{CTC}=29 \mathrm{mmol}_{\mathrm{c}} \mathrm{dm}^{-3} \mathrm{e} \mathrm{V}=25 \%$.

$\mathrm{O}$ delineamento experimental foi inteiramente casualizado em esquema fatorial $3 \times 3$, com quatro repetições. Os tratamentos constituíram de três cultivares: Caiapó - grupo tradicional, Primavera grupo intermediário, e Maravilha - grupo moderno, e três doses de B (0, 3 e $\left.6 \mathrm{mg} \mathrm{dm}^{-3} \mathrm{de} \mathrm{B}\right)$, sendo a fonte utilizada o bórax (110 $\mathrm{g} \mathrm{kg}^{-1}$ de B). Cada unidade experimental constituiu-se de um vaso plástico de $10 \mathrm{~L}$, que continha $8 \mathrm{dm}^{3}$ de solo e três plantas. Cada vaso recebeu $100 \mathrm{mg} \mathrm{dm}^{-3}$ de $\mathrm{N}\left(50 \mathrm{mg} \mathrm{dm}^{-3}\right.$, na semeadura, e $50 \mathrm{mg} \mathrm{dm}^{-3}$, em cobertura, no início do estádio de perfilhamento), $150 \mathrm{mg} \mathrm{dm}^{-3}$ de $\mathrm{P}$, $100 \mathrm{mg} \mathrm{dm}^{-3}$ de Ke $5 \mathrm{mg} \mathrm{dm}^{-3}$ de Zn, juntamente com a aplicação dos tratamentos com B. Antes da aplicação dos tratamentos, a terra utilizada recebeu calagem, para elevar a saturação por bases a $70 \%$, pela aplicação de calcário dolomítico, PRNT $93 \%$.

Quando as plantas se encontravam no estádio de diferenciação floral, 70 dias após a emergência, foi realizada a colheita do experimento. Uma amostra do sistema radicular foi lavada em água corrente sobre peneira com malha de $0,5 \mathrm{~mm}$ e armazenada em coletor universal com solução alcoólica $70 \%$ em ambiente refrigerado. As avaliações foram feitas em um "scanner", desenvolvido para esse fim, acoplado a um computador dotado de software específico, que utiliza como princípio o método proposto por Tennant (1975). Nesse equipamento, determinaram-se o comprimento (m/planta), a superfície ( $\mathrm{cm}^{2} /$ planta) e o diâmetro $(\mathrm{cm})$. Após essas avaliações, as amostras foram secas em estufa a $65^{\circ} \mathrm{C}$, para posterior determinação de matéria seca radicular ( $\mathrm{mg} / \mathrm{vaso})$. Também foram avaliados a produção de matéria seca e o teor de boro da parte aérea.

Os dados obtidos foram submetidos à analise de variância, e as médias comparadas pelo teste DMS a $5 \%$, por meio do programa estatístico SISVAR, versão 4.2 .

\section{RESULTADOS E DISCUSSÃO}

Os três genótipos de arroz de terras altas (Oryza sativa L.) apresentaram variabilidade de resposta à adubação com B no solo. O aumento das doses foi prejudicial ao crescimento radicular e da parte aérea, não existindo a possibilidade de constatar uma dose adequada.

A aplicação de B reduziu o comprimento radicular dos cultivares Caiapó e Primavera (Quadro 1), sendo a dose de $6 \mathrm{mg} \mathrm{dm}^{-3}$ tóxica em relação à dose de $0 \mathrm{mg} \mathrm{dm}^{-3}$. No entanto, já na dose de $3 \mathrm{mg} \mathrm{dm}^{-3}$, iniciou-se o processo de toxidez. Não houve variabilidade entre os cultivares de arroz para comprimento radicular.
A utilização de doses acima de $3 \mathrm{mg} \mathrm{dm}^{-3}$ de B pode levar ao desequilíbrio químico desse nutriente no solo, prejudicando o comprimento radicular em determinados cultivares de arroz de terras altas, como Primavera e Caiapó, tendo como conseqüência menor absorção de água e nutrientes, limitando o crescimento da parte aérea e, possivelmente, a produtividade do arroz nesse ecossistema. Fageria et al. (2003) afirmaram que teores superiores a $3 \mathrm{mg} \mathrm{dm}^{-3} \mathrm{de} B$ no solo são considerados tóxicos à cultura do arroz de terras altas.

Vale destacar que o cultivar Maravilha também apresentou diminuição de comprimento radicular, de $11 \mathrm{~m} /$ planta, entre a menor e a maior dose de B aplicada, valor próximo ao da Primavera e Caipó, 13 e $15 \mathrm{~m} /$ planta, respectivamente. No entanto, tal diferença obtida não foi significativa (Quadro 1). Essas reduções para comprimento radicular correspondem a 23 \% no cultivar Caiapó, 20 \% no Primavera e $17 \%$ no Maravilha (Figura 1). Os valores do comprimento radicular em plantas de arroz de terras altas estão próximos aos reportados por Crusciol et al. (2005).

Genótipos de arroz de terras altas que não apresentarem redução do comprimento radicular em razão do aumento das doses de $\mathrm{B}$ no solo, possivelmente conseguirão melhor exploração do solo, permitindo maior absorção de nutrientes nas camadas superficiais e de água nas subsuperficiais. Rosolem (1995) e Mello Ivo \& Mielniczuk (1999) atribuem ao aumento do comprimento radicular a maior eficiência para absorção específica de nutrientes em virtude da dimensão horizontal das células da raiz.

Com relação ao diâmetro radicular, verificou-se efeito das doses de B nos cultivares Primavera e Caiapó (Quadro 1). No cultivar Primavera, a aplicação de $3 \mathrm{mg} \mathrm{dm}^{-3}$ provocou aumento do diâmetro de raiz, enquanto, no Caiapó, isso foi constatado na dose de $6 \mathrm{mg} \mathrm{dm}^{-3}$. No cultivar Maravilha, não houve efeito da adição de B nesta variável.

Comparando cultivares dentro de cada dose, foram encontrados resultados distintos entre os cultivares nas doses de 3 e $6 \mathrm{mg} \mathrm{dm}^{-3}$ de B, tendo o Primavera apresentado maior diâmetro que o Maravilha já na dose de $3 \mathrm{mg} \mathrm{dm}^{-3}$, com valor de $0,014 \mathrm{~cm}$, e essa diferença foi ainda maior na dose de $6 \mathrm{mg} \mathrm{dm}^{-3}$, com $0,016 \mathrm{~cm}$. Esse efeito foi constatado também nos cultivares Caiapó e Maravilha, porém apenas na dose de $6 \mathrm{mg} \mathrm{dm}^{-3}$, com diferença de 0,014 cm.

$\mathrm{O}$ comportamento diferenciado entre os cultivares de arroz, quanto ao diâmetro radicular, pode ser atribuído à característica genética específica a cada planta. Com melhoramento genético, aumentou-se a tolerância dos cultivares aos estresses ambientais, fato que pode ser constatado no cultivar Maravilha (grupo Moderno) que foi mais tolerante ao aumento de B no solo.

Como o B é muito pouco translocado na planta e muito exigido nas regiões meristemáticas das raízes, onde são sintetizadas as auxinas (Barber, 1995), faz-se 
Quadro 1. Produção de matéria seca da parte aérea e de raiz, comprimento, superfície, volume radicular, diâmetro radicular e teor de boro de acordo com as doses de boro e cultivares

\begin{tabular}{|c|c|c|c|c|}
\hline \multirow{2}{*}{ Cultivar } & \multicolumn{3}{|c|}{ Dose de boro em $\mathrm{mg} \mathrm{dm}^{-3}$} & \multirow{2}{*}{ C.V. } \\
\hline & $\mathbf{0}$ & 3 & 6 & \\
\hline & \multicolumn{4}{|c|}{ Comprimento radicular (m/planta) } \\
\hline Maravilha & $62 \mathrm{aA}$ & $60 \mathrm{aA}$ & $52 \mathrm{aA}$ & \\
\hline Primavera & $64 \mathrm{aA}$ & $63 \mathrm{aAB}$ & $51 \mathrm{aB}$ & 11 \\
\hline \multirow[t]{2}{*}{ Caiapó } & $65 \mathrm{aA}$ & 56 aAB & $50 \mathrm{aB}$ & \\
\hline & \multicolumn{4}{|c|}{ Diâmetro radicular (cm) } \\
\hline Maravilha & $0,051 \mathrm{aA}$ & $0,049 \mathrm{bA}$ & $0,045 \mathrm{bA}$ & \\
\hline Primavera & $0,053 \mathrm{aB}$ & $0,063 \mathrm{aA}$ & $0,061 \mathrm{aA}$ & 8 \\
\hline \multirow[t]{2}{*}{ Caiapó } & $0,046 \mathrm{aB}$ & $0,044 \mathrm{bB}$ & 0,059 aA & \\
\hline & \multicolumn{4}{|c|}{ Superfície radicular $\left(\mathrm{cm}^{2} /\right.$ planta $)$} \\
\hline Maravilha & $90 \mathrm{bA}$ & $88 \mathrm{bA}$ & $79 \mathrm{abA}$ & \\
\hline Primavera & $106 \mathrm{abAB}$ & $127 \mathrm{aA}$ & $100 \mathrm{aB}$ & 13 \\
\hline \multirow[t]{2}{*}{ Caiapó } & $112 \mathrm{aA}$ & $103 \mathrm{bA}$ & $65 \mathrm{bB}$ & \\
\hline & \multicolumn{4}{|c|}{ Matéria seca de raiz (g/planta) } \\
\hline Maravilha & $20 \mathrm{bA}$ & $20 \mathrm{bA}$ & $16 \mathrm{bB}$ & \\
\hline Primavera & 29 aA & 26 aA & $17 \mathrm{bB}$ & 9 \\
\hline \multirow[t]{2}{*}{ Caiapó } & 29 aA & $27 \mathrm{aAB}$ & $24 \mathrm{aB}$ & \\
\hline & \multicolumn{4}{|c|}{ Matéria seca da parte aérea (g/planta) } \\
\hline Maravilha & $18 \mathrm{bA}$ & $17 \mathrm{bAB}$ & $13 \mathrm{bB}$ & \\
\hline Primavera & $25 \mathrm{aA}$ & $25 \mathrm{aA}$ & $15 \mathrm{bB}$ & 10 \\
\hline \multirow[t]{2}{*}{ Caiapó } & $27 \mathrm{aA}$ & $25 \mathrm{aAB}$ & $22 \mathrm{aB}$ & \\
\hline & \multicolumn{4}{|c|}{ Teor de B na parte aérea $\left(\mathrm{mg} \mathrm{kg}^{-1}\right)$} \\
\hline Maravilha & $76 \mathrm{aB}$ & $112 \mathrm{aB}$ & $210 \mathrm{aA}$ & \\
\hline Primavera & $61 \mathrm{aC}$ & $108 \mathrm{abB}$ & $152 \mathrm{bA}$ & 18 \\
\hline Caiapó & $51 \mathrm{aB}$ & $75 \mathrm{bB}$ & $115 \mathrm{cA}$ & \\
\hline
\end{tabular}

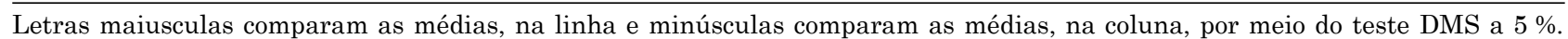

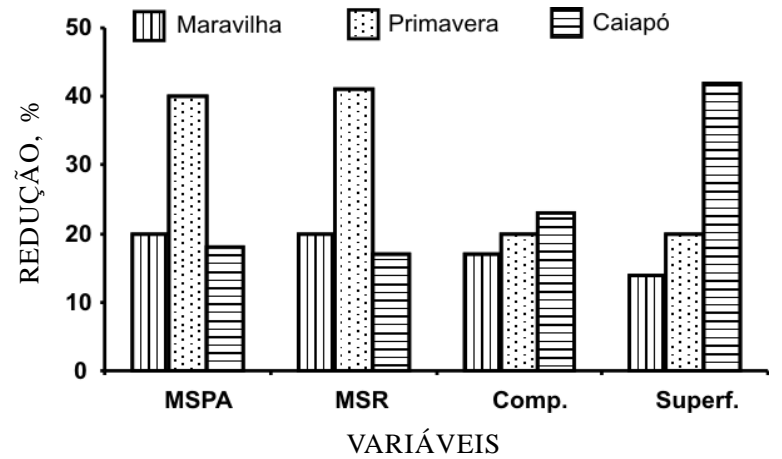

Figura 1. Redução em percentagem entre a menor e a maior dose de boro no solo para as variáveis matéria seca de parte aérea (MSPA), matéria seca de raiz (MSR), comprimento (Comp.) e superfície (Superf.) radiculares.

necessária a absorção nessa região específica da raiz. Então o cultivar Maravilha, apresentando menor diâmetro radicular, pode aumentar a velocidade de absorção e translocação desse nutriente, pois, quanto menor a espessura, menor o caminho que os elementos têm para percorrer desde a plasmalema até aos vasos de xilema e floema. Os cultivares Primavera e Caiapó apresentariam menor velocidade translocação dos nutrientes, tanto pelo apoplasto (intercelular) como no simplasto (intracelular).

Pode-se inferir (Quadro 1) que o aumento do diâmetro radicular nos cultivares Primavera (3 e $6 \mathrm{mg} \mathrm{dm}^{-3}$ ) e Caiapó ( $6 \mathrm{mg} \mathrm{dm}^{-3}$ ) seria um mecanismo de defesa da planta às altas concentrações de $\mathrm{B}$ no solo, e, pelo fato de o cultivar Maravilha não ter o diâmetro radicular médio alterado pelos tratamentos com B, é possível que esse cultivar tenha maior tolerância a altos teores desse nutriente no solo.

Os genótipos Primavera e Caiapó apresentaram incremento no diâmetro radicular, entre a menor e a maior dose de B no solo, de 15 e $28 \%$, respectivamente (Figura 2). No entanto, o cultivar Maravilha não foi afetado (redução de 11 \% do diâmetro radicular, nãosignificativa, em virtude do aumento das doses B no solo).

As características morfológicas que apresentam maiores influências no processo de absorção são o 
comprimento e o diâmetro (Rosolem 1995). Uma vez que ambas as características foram afetadas pelos tratamentos, pode-se afirmar que a presença de B no solo em excesso é fator prejudicial ao crescimento radicular e, conseqüentemente, à absorção de água e nutrientes.

A superfície radicular depende do comprimento e do diâmetro radicular, portanto, tal variável foi também prejudicada com a dose de $6 \mathrm{mg} \mathrm{dm}^{-3} \mathrm{de} \mathrm{B}$, nos cultivares Primavera e Caiapó (Quadro 1), denotando que o excesso de B no solo prejudicou o crescimento radicular desses dois cultivares. O cultivar Maravilha foi o único que não apresentou interação para doses, característica semelhante ocorreu para comprimento e diâmetro radicular.

Constatou-se variabilidade entre genótipos para superfície radicular: na dose de $3 \mathrm{mg} \mathrm{dm}^{-3}$, o cultivar Primavera mostrou-se superior ao Caiapó e ao Maravilha, enquanto, na dose de $6 \mathrm{mg} \mathrm{dm}^{-3}$, o Primavera foi superior apenas ao Caiapó.

Os resultados de crescimento radicular (comprimento, diâmetro e superfície), possivelmente influenciaram a produção de matéria seca de raiz (MSR) e de parte aérea (MSPA) dos cultivares de arroz de terras altas. Com o aumento das doses de B, tanto a MSR quanto a MSPA não apresentaram diferença significativa entre as doses 0 e $3 \mathrm{mg} \mathrm{dm}^{-3}$ de $\mathrm{B}$, entretanto, na dose de $6 \mathrm{mg} \mathrm{dm}^{-3} \mathrm{de} \mathrm{B}$, ocorreu redução dos valores destas variáveis, tornando-se a maior dose prejudicial, tanto para MSR como para MSPA, nos três cultivares de arroz.

A MSPA depende do desenvolvimento da MSR, portanto as condições do meio em que as raízes de arroz se desenvolveram caracterizaram efeito tóxico na dose de $6 \mathrm{mg} \mathrm{dm}^{-3}$. O cultivar Maravilha apresentou os menores valores de matéria seca de parte aérea e raiz em todas as doses, em relação aos demais cultivares, com exceção apenas na dose de $6 \mathrm{mg} \mathrm{dm}^{-3}$ de B, quando o comportamento foi igual ao do cultivar Primavera. Esses resultados corroboram os obtidos por Fageria et al. (2003), que observaram redução da produção de matéria seca de raiz, quando os teores de B no solo estiveram acima de $3,0 \mathrm{mg} \mathrm{dm}^{-3}$.

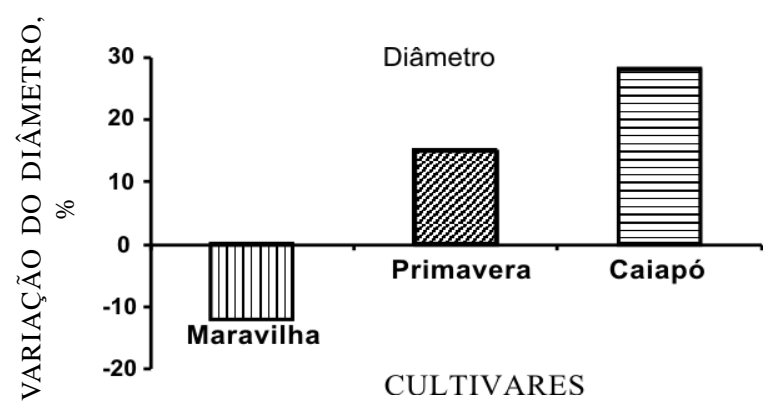

Figura 2. Variação em percentagem do diâmetro radicular entre os tratamentos que receberam a menor e a maior dose de boro aplicado no solo.
Foram constatados índices, relativamente próximos, de redução da produção de matéria seca de raiz e da parte aérea para os cultivares Maravilha (20 \%), Primavera (41\%) e Caiapó (17 \%), o que pode estar relacionado com a redução do comprimento radicular (Figura 1) e aumento do diâmetro radicular (Figura 2) em razão dos níveis elevados de B.

$\mathrm{O}$ aumento dos teores de $\mathrm{B}$ no solo promoveu maior absorção desse elemento nos três cultivares de arroz de terras altas, tendo a dose de $6 \mathrm{mg} \mathrm{dm}^{-3}$ apresentado os maiores valores de absorção. O cultivar Maravilha apresentou os maiores teores de B em todas as doses. Esse cultivar faz parte do grupo moderno que é caracterizado por materiais melhorados, apresentando porte baixo, folhas eretas e raízes com maior capacidade de absorção de nutrientes em relação aos demais cultivares (Fageria, 1999). No entanto, outros fatores também influem na disponibilidade e na absorção de $\mathrm{B}$ pelas plantas, tais como $\mathrm{pH}$, textura, umidade e temperatura do solo (Gupta et al., 2000).

$\mathrm{O}$ aumento do teor de B no solo favoreceu, ainda mais, o diferencial de potencial químico entre o $\mathrm{B}$ do solo e da planta, permitindo a passagem direta do elemento pela parede bilipídica, ocasionada pela ausência de cargas (Dordas \& Brown, 2001). Essa passagem preferencial do nutriente, considerando as doses aplicadas no solo, pode explicar o excesso na absorção de B nos três cultivares de arroz de terras altas (Quadro 1), prejudicando seu crescimento radicular e a matéria seca da parte aérea.

Segundo Fageria (1984), as folhas de plantas de arroz de terras altas na fase de perfilhamento revelam diferentes respostas à adubação com $\mathrm{B}$, a saber: teores de $\mathrm{B}$ menores de $15 \mathrm{mg} \mathrm{kg}^{-1}$ são considerados como deficientes, teores entre 15 e $20 \mathrm{mg} \mathrm{kg}^{-1}$ são críticos; entre 20-100 mg kg-1, adequados, e, acima de $100 \mathrm{mg} \mathrm{kg}^{-1}$, como tóxicos. Com base nos dados de MSR e MSPA (Quadro 1), valores de 210, 152 e $115 \mathrm{mg} \mathrm{kg}^{-1}$ de B, para os cultivares Maravilha, Primavera e Caiapó, são considerados tóxicos a esses genótipos. Yu et al. (1998) relatam que cada cultivar de arroz exibe diferente classe de resposta à adubação com B, enquanto Dordas \& Brown (2001) atribuem esses diferentes resultados entre genótipos à existência tanto do mecanismo passivo como do ativo para absorção desse elemento pelas plantas de arroz.

Com o aumento das doses de B adicionadas ao solo, o cultivar Maravilha apresentou os maiores teores sem sofrer alterações significativas para comprimento, superfície e diâmetro radicular, o que demonstra certa tolerância à elevação das doses de B no solo. No entanto, a dose de $6 \mathrm{mg} \mathrm{dm}^{-3}$ causou redução para MSPA e MSR para esse cultivar. A relativa tolerância do cultivar Maravilha para as variáveis radiculares provavelmente se deve a mecanismos adaptativos para se proteger da toxidez de B no solo. Um desses mecanismos que ocorre nas raízes envolve a complexação do boro pela dehydrogenase de glutamato em formas não-tóxicas às plantas (Mahaboodi et al., 2002). 
O cultivar Caiapó, apesar de apresentar o maior valor de produção de matéria seca de raiz, quando tratada com $6 \mathrm{mg} \mathrm{dm}^{-3} \mathrm{de} \mathrm{B}$, apresentou o menor teor de B. Isto indica que a absorção não está relacionada com o crescimento radicular, mas, sim, com outras características fisiológicas do sistema radicular (Rosolem, 1995).

\section{CONCLUSÕES}

1. A dose de $6 \mathrm{mg} \mathrm{dm}^{-3}$ é prejudicial à produção de matéria seca da parte aérea e das raízes para o arroz de terras altas.

2. O cultivar Maravilha apresentou-se mais tolerante à elevação das doses de B no solo para as variáveis comprimento, diâmetro e superfície radicular, além de apresentar maior capacidade de absorção de B.

\section{LITERATURA CITADA}

BARBER, S.A. Soil nutrient bioavalability: a mechanistic approach. 2.ed. New York, Jonh Wiley \& Sons, 1995. $414 \mathrm{p}$.

BELLALOUI, N.; YADAVC, R.C.; CHERN, M.S.; HU, H.; GILLEN, A.M.; GREVE, C.; DANDEKAN, A.M.; RONALD, P.C. \& BROWN, P.C. Transgenically enhanced sorbitol synthesis facilitates phloem-boron mobility in rice. Physiol. Plant., 117:79-84, 2003.

CRUSCIOL, C.A.C.; MACHADO, J.R.; ARF, O.\& RODRIGUES, A.F. Matéria seca e absorção de nutrientes em função do espaçamento e da densidade de semeadura em arroz de terras alta. Sci. Agric., 56:63-70, 1999.

CRUSCIOL, C.A.C.; MAUAD, M.; ALVAREZ, R.C.F.; LIMA, E.V. \& TIRITAN, C.S. Doses de fósforo e crescimento radicular de cultivares de arroz de terras altas, Bragantia, 64:643-649, 2005.

DORDAS, C. \& BROWN, P.H. Evidence mediated channel in transport of boric acid in Squash. Plant Soil, 235:95-103, 2001.

FAGERIA, N.K. Manejo da calagem e adubação do arroz In: BRESEGHELLO, F. \& STONE, L.F. Tecnologia para o arroz de terras altas. Santo Antônio de Goiás, Embrapa Arroz e Feijão, 1998. p.67-78.

FAGERIA, N.K. Nutrição mineral. In: VIEIRA, N.R.A; SANTOS, AB. \& SANT'ANA, E.P. eds. A cultura do arroz no Brasil. Santo Antônio de Goiás, Embrapa Arroz e Feijão, 1999. p.329-353.

FAGERIA, N.K. Resposta de arroz de terras altas à correção de acidez em solo do cerrado. Pesq. Agropec. Bras., 35:2303-2307, 2000.
FAGERIA, N.K.; BARBOSA FILHO, M.P. \& STONE, L.F. Doses e teores adequados e tóxicos de micronutrientes no solo e plantas de culturas anuais. In: CONGRESSO BRASILEIRO DE CIÊNCIA DO SOLO, 19., Ribeirão Preto, 2003. Resumos. Ribeirão Preto, 2003. CD-ROM.

GUPTA, U.C. Deficiency, sufficiency and toxicity level of boron in crop. In: GUPTA, U.C., ed. Boron an its role in crop production. Boca Raton, CRC. Ross, 2000. p137-145.

KIEHL, L.J. Manual de Edafologia - relações solo-planta. São Paulo, Agronômica Ceres, 1979. 262p.

LOPES, M.S.; SANTOS, O.S.; CABRAL, I.T. \& IOCHPE, B. Efeito de micronutrientes sobre o rendimento de grãos de arroz irrigado. In: REUNIÃO DA CULTURA DO ARROZ IRRIGADO, 14., Pelotas, 1985. Anais. Pelotas, Embrapa - CPATB, 1985. 226-234p.

LUND, S.T.; SMITH, A.G. \& HACKETT, W.P. Cuttings of tabacco mutant, rac, undergo cell divisions but do not initiate adventitious roots inresponse to exogenous auxina. Physiol. Plant., 97:372-380, 1996.

MAHABOODI, H.; YUCEL M. \& OKTEM, H.A. Nitrate redutase and glutamate dehydrogenase activities of resistant and sensitive cultivars of wheat and barley under boron toxicity. J. Plant Nutr., 25:1829-1837, 2002.

MALAVOLTA, E. \& FORNASIERI FILHO, D. Nutrição mineral da cultura do arroz. In: FERREIRA, M.E.; YAMADA, T. \& MALAVOLTA, E., eds. Cultura do arroz de sequeiro; fatores afetando a produtividade. Piracicaba, Instituto da Potassa \& Fosfato; Instituto Internacional da Potassa, 1983. 422p.

MARSCHNER, H. Mineral nutrition of higher plants. New York, Academic Press, 1995. 674p.

MELLO IVO, W.M.P. \& MIELNICZUK, J. Influência da estruturação do solo na distribuição e na morfologia do sistema radicular do milho sob três métodos de preparo. R. Bras. Ci. Solo, 23:135-143, 1999.

OBATA, H. Micro essential elements. In: MATSUO, T.; KUMAZAWA, K.; ISHII, R.; ISHIHARA, K. \& HIRATA, H., eds. Science of the rice plant - volume two physiology. Food and Agriculture Police Research Center.Tokyo, 1995. 402-417p.

ONO, E.O. \& RODRIGUES, J.D. Aspecto da fisiologia do enraizamento de estacas caulinares. Jaboticabal, Universidade Estadual Paulista, 1996. 83p.

RAIJ. B.van.; ANDRADE, J.C.; CANTARELLA, H. \& QUAGGIO, J.A. Análise química para avaliação da fertilidade de solos tropicais. Campinas, Instituto Agronômico, 2001. 285p.

ROSOLEM, C.A. Relação solo-planta na cultura do milho. Jaboticabal, Funep, 1995. 53p.

SCIVITTARO, W.B. \& MACHADO, O.M. Adubação e calagem para a cultura do arroz irrigado. In: GOMES, A.S. \& MAGALHÃES JUNIOR, A.M., eds. Arroz irrigado no sul do Brasil. Brasília, DF, Embrapa Informações Tecnológicas, 2004. 259-297p.

TENNANT, D. A test of a modifical line intersect method of estimating root length. J. Ecol., 63:995-1001, 1975. 